\title{
Eldre personer er sårbare i ekstreme værsituasjoner
}

\author{
Anette Hylen Ranhoff \\ Universitetseksjonen Geriatrisk avdeling, Ullevål Universitetsykehus, 0407 Oslo \\ Korrespondanse: Anette Hylen Ranhoff, Mottagelsen, Kirurgisk divisjon, Ullevål Universitetsykehus, 0407 Oslo \\ E-post: ahranhoff@yahoo.no Telefax: 22117351
}

\begin{abstract}
SAMMENDRAG
I fjor sommer ble Europa rammet av en hetebølge og tusenvis av eldre mennesker døde. Sammenhengen mellom helsetilstand og påvirkning av klima er kompleks og medisinske, sosiale og miljømessige faktorer er involvert. Imidlertid er hete- og kulderelaterte sykdommer, skade og død i høy grad mulig å forebygge, og det er behov for å analysere denne situasjonen og andre ekstreme værsituasjoner for å kunne sikre helsen til eldre personer ved liknede hendelser i fremtiden.

Artikkelen gir en oversikt over litteratur som omhandler sykelighet og dødelighet som følge av ekstreme værforhold: hete, kulde og situasjoner der transport, elektrisitet og andre leveranser er begrenset, som etter en orkan, enorme snøfall eller liknende. Sammenhenger mellom sykelighet, dødelighet og temperatur i alminnelighet bli også omtalt, med spesielt fokus på de eldre.

Eldre som lever alene og er sosialt isolerte, og spesielt de som har funksjonshemning eller kognitiv svikt har høyest risiko for sykdom, skade og død i ekstreme værsituasjoner. Dette kan trolig i stor grad forebygges. Det anbefales at alle kommuner har kriseplaner for naturkatastrofer og ekstreme værsituasjoner som spesielt inneholder tiltak rettet mot sårbare eldre. Planene bør inneholde generell alarmering og informasjon samt systemer for oppsøkende virksomhet overfor risikogrupper.
\end{abstract}

Ranhoff AH. Elderly people are vulnerable in extreme weather situations. Nor J Epidemiol 2004; 14 (2): 199-205.

\section{ENGLISH SUMMARY}

The 2003 heat wave in Europe was responsible for the deaths of thousands of elderly people. Heat- and cold-related illnesses, injuries and deaths are supposed to be largely preventable, and it is a need for analysing this situation and other situations with extreme weather conditions where elderly people are believed to be particularly vulnerable.

This article is a review of the literature concerning morbidity and mortality in extreme weather conditions like heat, cold and situations where transportation, electricity, and other supplies are limited as a consequence of extreme weather such as after a hurricane or an enormous snowfall. Associations between mortality, morbidity and temperature in general are also discussed with focus on the elderly population.

The elderly are at high risk for illnesses, injuries and death in extreme weather conditions. There are numerous reports from heat waves, but also cold-related problems are well documented. Other risk factors are disability, cognitive impairment, chronic disease, the use of special drugs and social isolation. Many risk factors are common for heat-, and cold-related problems, and also for other situations like after a hurricane or an enormous snowfall. The frailest elderly are at the highest risk.

In situations with extreme weather conditions, we recommend local and central authorities to have emergency plans with special adaptations to the needs of elderly people and other vulnerable groups. These plans should include general warning and information and systems for preventive visits to high-risk groups.

I fjor sommer ble Europa, særlig Frankrike og Italia, rammet av en hetebølge og tusenvis av eldre mennesker døde (1-3). Sammenhengen mellom helsetilstand og påvirkning av klima er kompleks og medisinske, sosiale og miljømessige faktorer er involvert. Imidlertid er hete- og kulderelaterte sykdommer, skade og død i høy grad mulig å forebygge (4), og det er behov for å analysere denne situasjonen og andre ekstreme værsituasjoner. Det viktigste er å kunne sette i verk forebyggende og skadebegrensende tiltak for å hindre at liv går tapt og for å sikre helsen til eldre personer ved liknede hendelser i fremtiden.

Hete- og kulderelaterte skader og død er ikke klart definert, men omfatter skader og død hvor eksposisjon for ekstrem hete eller kulde enten direkte forårsaket dødsfallet/skaden eller i vesentlig grad bidro til det, og hvor andre årsaker til hypertermi eller hypotermi er ekskludert (5). Hete- og kulderelaterte skader og død er altså ikke synonymt med overdødelighet i perioder med kulde eller hete. Spesielt for hypotermi (ned- 
kjøling til $<35^{\circ} \mathrm{C}$ i kjernetemperatur) kan det være vanskelig å skille om det er en konsekvens av sykdom eller av lav temperatur i omgivelsene (6-8). Hypotermi innendørs skyldes ofte kollaps forårsaket av sykdom hos en lettkledd pasient som ikke var i sengen (9).

Oversykelighet og overdødelighet relatert til andre ekstreme værsituasjoner der transport, elektrisitet og andre leveranser er mangelfulle, slik som etter en orkan eller et enormt snøfall er rapportert, men direkte årsaker og mekanismer er lite studert (10-12).

Denne artikkelen gir en oversikt over litteratur som omhandler sykelighet og dødelighet hos eldre som følge av ekstreme værforhold: hete, kulde og situasjoner der transport, elektrisitet og andre leveranser er begrenset, som etter en orkan eller ved enorme snøfall. Sammenhenger mellom dødelighet og temperatur i alminnelighet vil også bli omtalt, med spesielt fokus på den eldre del av befolkningen. Hensikten er å gi en oversikt over epidemiologien ved sykdom, skade og død i relasjon til værforhold for om mulig å bekrefte at eldre personer har spesielt høy risiko og å finne andre risikofaktorer enn alder som kan hjelpe oss til å identifisere de mest sårbare eldre som mål for spesielle tiltak. En oversikt over aktuelle tiltak, med bakgrunn i erfaringer gjengitt i litteraturen, vil også bli diskutert for å kunne gi anbefalinger.

\section{MeTODE}

Artikkelen er basert på søk i MEDLINE med søkeord "elderly" AND "heat", "heatwave", "heat-related", "cold", "cold-related", hurricane", "tornado", "snow" og "snowfall" for å finne rapporter og epidemiologiske studier som kunne gi et bilde av eldre personers sårbarhet i ekstreme værsituasjoner. Det er også søkt med søkeord "morbidity" og "excess mortality" AND "heat" og "cold" for å finne artikler som belyser sammenhenger mellom sykelighet, dødelighet og temperatur. Søkeordene "hyperthermia" og "hypothermia" ble brukt for å finne litteratur både om epidemiologiske forhold og mekanismer bak skader og død som følge av hypotermi og hypertermi. Fra disse søkene er det plukket ut interessante artikler som særlig omhandler eldre.

\section{RESUlTATER}

\section{Eldre personer er sårbare i ekstreme varsituasjoner}

Konsekvensene av hetebølgen i Frankrike sommeren 2003 er nå analysert av instituttet som overvåker befolkningens helsetilstand (Institut de Veille Sanitaire), og det er anslått at 11435 mennesker døde og at 80\% av disse var 75 år og eldre. De største byene ble hardest rammet, og i Paris steg dødeligheten med over $200 \%$ i den aktuelle perioden. Det bemerkes også at hetebølgen kom på det verst tenkelige tidspunkt, nemlig når både familie og mange ansatte i helse- og pleiesektoren var på ferie (1). I Italia ble det registrert en overdødelighet på vel 4000 (medio juli til medio august) og i Spania vel 3000 dødsfall (primo juni til ultimo august). Også i disse landene var det hovedsakelig eldre som døde $(13,14)$. Hetebølgen i Europa sommeren 2003 (1-3,15) er ikke den eneste situasjonen hvor eldre personer har vært ofre for ekstreme værforhold. Fra hetebølger i USA, Japan, Taiwan, Australia og Europa, er det tidligere rapportert at eldre er spesielt sårbare (16-31). Eldre personer som bor alene og som ikke er i stand til å forlate boligen daglig har den høyeste risiko. Hjerte-kar sykdommer og andre kroniske sykdommer, kognitiv svikt, bruk av psykoaktive medikamenter og diuretika, å være sengeliggende, sosialt isolert og uten tilgang til luftkondisjonering er også vist å være viktige risikofaktorer. Flest heterelaterte dødsfall er observert i byene, og særlig i selve bykjernen. Dette kan delvis forklares ved at det er høy befolkningstetthet, men også ved at det er mindre effektiv nattlig avkjøling i slike områder $(32,33)$. Det er også rapporter om økning av dødsfall i pleieinstitusjoner for eldre under hetebølger $(3,34,35)$. Flere studier viser at økningen særlig gjelder pleieinstitusjoner uten fungerende luftkondisjonering $(34,36)$.

Når det gjelder assosiasjonen mellom hete og sykelighet er den ikke så godt dokumentert som for dødelighet. I perioder med intens hete er det rapportert fra akuttmottak på sykehusene at det er en generell økning av henvendelser. Særlig gjelder dette besvimelser, kvalme, slapphet og hetekramper $(17,19,24,37)$. En retrospektiv studie av demente under hetebølgen i Italia i 2003 viste en økning i forekomsten av atferdsproblemer (38) og under hetebølgen som rammet Storbritannia i 1983 ble det registrert en økning i hjerneslag (39).

Ved en nasjonal gjennomgang av dødsattester i USA ble det funnet mange kulderelaterte dødsfall som kunne vært unngått (40). Ellers er dokumentasjonen fra perioder med ekstrem kulde mer sparsom og omhandler enkeltpasienter eller noen få subjekter. Det amerikanske Centre of Disease Control's (CDC's) rapportering av hypotermi-relaterte dødsfall viser at personer som er 75 år og eldre har spesielt høy risiko (6). De fleste av de eldre ofrene har demenssykdom (6-8) og andre risikofaktorer er sykdom som gir funksjonshemning, hypotyreose, underernæring og bruk av betablokkere og nevroleptika $(41,42)$. Hypotermi-dødsfall i byer rammer oftest eldre og personer der misbruk av alkohol eller andre rusmidler er involvert (8).

Effekten av andre ekstreme værsituasjoner, som enorme snøfall og orkan, på den eldre befolkningen er mindre studert. Snøfall på mer enn $3 \mathrm{~cm}$ i Pennsylvania, USA, er vist å øke mortaliteten hos eldre, men også hos middelaldrende menn som følge av hjertesykdom, sykdommer i respirasjonsorganene og cerebrovaskulær sykdom (12). Høy alder er vist å være en risiko for død som følge av tornadoer (11). I Norge har vi erfaringer fra orkanen som rammet Nord-Vestlandet første nyttårsdag 1992 og førte til store ødeleggelser og sviktende elektrisitetsforsyning i deler av Nordmøre 
i opptil fem døgn. Andelen av eldre som ble rammet var høy (18 av 56). En eldre mann døde av hypotermi og ytterligere 17 eldre ble behandlet hos lege eller $\mathrm{i}$ sykehus på grunn av problemer direkte relatert til orkanen eller relatert til kulde og mørke som følge av at de var strømløse. Ni personer som var 75 år og eldre hadde falt inne i mørket og ytterligere tre ble behandlet for mild til moderat hypotermi (10).

Tabell 1. Risikofaktorer for hete- og kulderelaterte sykdommer, skader og død, samt sykdommer, skader og død ved andre ekstreme vær- og naturforhold (orkan, store snøfall).

\begin{tabular}{lccc}
\hline Risikofaktor & $\begin{array}{c}\text { Hete- } \\
\text { relatert }\end{array}$ & $\begin{array}{c}\text { Kulde- } \\
\text { relatert }\end{array}$ & $\begin{array}{c}\text { Orkan, } \\
\text { snøfall etc }\end{array}$ \\
\hline Alder & + & + & + \\
Kjønn: Kvinne & + & & + \\
$\quad$ Mann & + & + & \\
Kognitiv svikt & + & + & + \\
Fysisk funksjonssvikt & + & + & + \\
Kronisk sykdom & + & + & \\
Psykiatrisk sykdom & + & + & + \\
Sosial isolasjon & + & & \\
Ingen luftkondisjonering & & + & \\
Ingen sentralvarme & & + & \\
Alkohol & + & + & \\
Medikament overdose & + & + & \\
Bruk av psykofarmaka & + & & \\
Bruk av betablokker & & & + \\
Underernæring & & & +
\end{tabular}

\section{Dodelighet og omgivelsenes temperatur}

Dødelighet påvirkes av omgivelsestemperaturen når denne blir høy eller lav i forhold til det normale for området. Dette er mer uttalt for eldre enn for yngre individer (43). Antall månedlige dødsfall i England og Wales viser en sterk assosiasjon med utvendig temperatur for de fleste sykdommer med unntak av kreft. Det samme er vist for død forårsaket av hjerteinfarkt, hjerneslag og pneumoni i data fra England, Wales og New York $(43,44)$. I Storbritannia er det vist at fra $-10^{\circ} \mathrm{C}$ til $+20^{\circ} \mathrm{C}$ er det et nærmest lineært fall $\mathrm{i}$ dødelighet når temperaturen stiger (43). Dødeligheten er lavest ved $+20^{\circ} \mathrm{C}$, men øker så raskt med økende temperatur. Under $-10^{\circ} \mathrm{C}$ øker dødeligheten raskere med fallende temperatur. Dette gjelder særlig temperaturendringer som varer 7 dager eller mer (43). Assosiasjonen mellom vintertemperatur og dødelighet hos eldre varierer mellom forskjellige land i Europa og synes å være avhengig av sosioøkonomiske forhold og geografiske forhold. I Norge er det lavere overdødelighet om vinteren enn i England og Wales når effekten av influensaepidemier er korrigert for (45). Eurowinter gruppen har studert kulderelatert dødelighet og fant at denne hadde sammenheng med høy gjennomsnittlig vinter- temperatur, lav temperatur i oppholdsrom, mangelfull oppvarming av soverom og liten bruk av lue/hatt, hansker og ytterjakker utendørs (46). Det synes som om forskjellige befolkningsgrupper har forskjellige temperaturområder der dødeligheten er lavest. Disse temperaturområdene er signifikant lavere i nord enn i syd i Europa (47) og tilsvarende er funnet i USA $(48,49)$. Ved en spesiell temperatur (lav eller høy), i hvert land eller region, vil dødeligheten begynne å stige raskt (43, 46-49). Dette synes imidlertid særlig å gjelde i temperert klima. Braga og medarbeidere fant $\mathrm{i}$ sin studie fra 12 byer geografisk spredd i USA at i relativt kalde byer var både for høye og for lave temperaturer assosiert med høy dødelighet, mens i varme byer hadde verken høy eller lav temperatur særlig effekt på dødeligheten (48).

Effekten av høye temperaturer på dødeligheten er mindre i områder med utbredt bruk av luftkondisjonering (50), mens høy luftfuktighet øker dødeligheten (51). Tidsfaktoranalyser viser at effekten av kulde blir akkumulert over flere dager (43) mens effekten av høy temperatur er begrenset til den dagen pasienten døde eller den foregående dag og den effekten er dobbelt så sterk som kuldeeffekten (52).

\section{Hvorfor er eldre personer spesielt sårbare?}

Eldre mennesker er spesielt sårbare for termisk stress (53). Dette kan forklares dels av normale aldringsprosesser som kjennetegnes ved redusert homeostase og organkapasitet, men også av høy forekomst av sykdommer og funksjonshemning. Eldre har lavere metabolisme og redusert evne til varmekonservering ved at skjelvemekanismen, som har til hensikt å produsere varme, er redusert. Svettemekanismen, som skal lede varme bort fra kroppen, er også redusert i høy alder. Mindre mengde underhudsfett er vanlig hos eldre og gir nedsatt isolasjon. Redusert homeostase gir dårligere temperaturregulering og regulering av væske- og elektrolyttbalansen, samt redusert postural balanse. Dette utgjør viktige risikofaktorer for hypotermi, heteslag, dehydrering og fall.

Den første fysiologiske respons på hete er en økning av hudens blodsirkulasjonen som gir økt varmetap gjennom utstråling, varmeledning og fordampning. Dette begrenses imidlertid av hjertets maksimale pumpeeffekt som kan være nedsatt som følge av aldring og hjertesvikt og kan føre til ukontrollert økning i kroppstemperaturen eller sirkulatorisk kollaps på grunn av overbelastning av hjertet (4). Hemokonsentrasjon er et typisk laboratoriefunn ved heteslag (54). Aldersavhengig svikt i reguleringen av væskebalansen, redusert tørstefølelse og nyresvikt vil disponere for dette.

Kjernetemperaturen faller vanligvis ikke hos en påkledd eldre person i hvile dersom han/hun ikke er utsatt for mer enn to timer i omgivelser med $9^{\circ} \mathrm{C}$ eller lavere. Dette kan imidlertid skje når eldre blir fanget på et gulv eller i en stol som følge av fall eller kollaps fra en akutt sykdom (9). Forhøyet blodtrykk og økt 
blodviskositet som opptrer i moderat kulde kan være viktige kausale faktorer for overdødelighet og oversykelighet om vinteren. Sesongvariasjonen i fibrinogenkonsentrasjonen hos eldre, med en økning om vinteren, er stor nok til å gi økt risiko for hjerteinfarkt og hjerneslag i årets kaldeste måneder (55).

Vanlige tilstander hos eldre vil bidra til ytterligere sårbarhet for termisk stress. For eksempel vil hypotyreose og underernæring gi økt risiko for kulderelaterte problemer. Kognitiv svikt, syn- og hørselsvikt vil redusere årvåkenheten for varme, kulde og andre potensielt farlige klimatiske situasjoner. Mange eldre kan også ha problemer med å reagere adekvat ved slike farer og dermed bli fanget $i$ en farlig situasjon. Kronisk sykdom, funksjonssvikt, kognitiv svikt og sosial isolasjon er assosiert med slike problemer.

\section{Tiltak for å hindre og begrense skade på eldre ved ekstreme varsituasjoner}

Tiltakene kan deles inn i generelle forbyggende tiltak, spesifikke forebyggende tiltak rettet mot risikogrupper og tiltak når det oppstår en krise.

Generelle forebyggende tiltak består av informasjon til den generelle befolkningen for å gjøre dem mer rustet til å takle en ekstrem værsituasjon, som hvordan å te seg for å unngå hete- eller kulderelaterte problemer. Effekten av slike tiltak er studert ved å observere forskjellige kohorter før og etter slik informasjon ble gitt. Bruken av luftkondisjonering og økt væskeinntak er to atferdsendringer som har vist seg å ha effekt når det gjelder å redusere heterelaterte dødsfall $(56,57)$. Heterelaterte dødsfall forkommer nå svært sjelden $\mathrm{i}$ North Carolina, USA, og dette forklares med utbredt bruk av luftkondisjonering (50). Den reduksjon i heterelaterte problemer som ble sett i USA under hetebølgen i 1999 sammenliknet med hetebølgen i 1995 kan ikke forklares ved forskjell i klimatiske forhold. Be- folkningen var trolig bedre forberedt og dette er et godt argument for folkeopplysning (58). Forebyggende tiltak kan også gis til definerte risikogrupper. I en studie fra Storbritannia organiserte en allmennpraktiker forbyggende hjemmebesøk til eldre med to eller flere risikofaktorer for hypotermi. Dette hadde imidlertid liten effekt og etter intervensjonen levde 17 av 24 pasienter fortsatt $\mathrm{i}$ omgivelser hvor de var i betydelig risiko for å utvikle hypotermi (59).

Sykehjemsbeboere er kjent for å ha den høyeste prevalens av sykelighet og funksjonssvikt og de har høy risiko for død under hetebølger $(3,34,35)$. Luftkondisjonering har vist seg å være et effektivt tiltak for å holde dødstallene $\mathrm{i}$ et sykehjem på normalt nivå under en hetebølge $(34,36)$.

Tiltak når det oppstår en krisesituasjon kan være provisoriske eller planlagte. I Philadelphia finnes et "Hot Weather-Health Watch Warning System" som aktiviseres når temperaturen går over et visst nivå. Dette kan ha spilt en rolle $\mathrm{i}$ å redusere døsfallene under hetebølgen i 1995 (60). Liknende systemer er nå utviklet i Frankrike som følge av hetebølgen i 2003 (61) samt i Roma, Shanghai, Toronto og diverse byer $\mathrm{i}$ USA (62).

Tiltakene etter orkanen på Nordmøre i 1992 var delvis provisoriske, men basert på kommunale kriseplaner. Skrøpelige eldre ble oppsøkt hjemme av den kommunale omsorgstjenesten og med bistand fra Sivilforsvaret. Det ble opprettet en provisorisk nødavdeling på det lokale sykehuset og sykehjem ble også brukt for å gi de skrøpeligste et trygt sted å være. Tilgang til oppvarmede offentlige bygg og varmt vann var viktige kommunale tiltak. Ved og alternative oppvarmingskilder ble distribuert av private. Effekten av disse tiltakene på eldres helsetilstand er ikke studert, men behov ble identifisert og hjelp gitt (10). Forslag til tiltak i en krisesituasjon vises i tabell 2.

Tabell 2. Tiltak for å forebygge og redusere skade og død hos eldre i ekstreme værsituasjoner.

1. Identifisere høyrisikogrupper blant de eldre: aleneboende, kronisk syke, funksjonshemmede, personer med kognitiv svikt.

2. Varslingsystem for signifikant hete, kulde eller andre farer.

3. Generell informasjon i radio, TV og andre medier (nett-sider, aviser):

a. Hvem er spesielt utsatt for skade og død (skrøpelige eldre etc.).

b. Hvem må ta affære (familie, naboer, venner, kommunale omsorgsapparat).

c. Praktiske råd adaptert til den aktuelle situasjonen: varme, avkjøling, væskeinntak, evakuering til et trygt oppholdssted.

d. Faresignaler: tegn og symptomer på hypotermi, hypertermi, dehydrering etc som krever kontakt med lege eller sykehusinnleggelse.

e. Hvor får man hjelp: Telefonnummer til AMK-sentral, kommunale omsorgstjenester etc.

4. Oppsøkende virksomhet for å finne personer i fare:

a. Hvem: familemedlemmer, naboer, venner, kommunale omsorgstjenester, sivilforsvaret, politi.

b. Metoder: Hjemmebesøk, telefonoppringning.

5. Velfungerende helse- og omsorgstjenester, organisering og profesjonell kompetanse:

a. Kapasitet og pasientflyt.

i. Evakuering for å dekke basale behov hos de eldre (riktig omgivelsestemperatur, mat og drikke, omsorg).

ii. Medisinsk behandling (lege- og sykehustjenester).

b. Medisinsk kompetanse som sikrer optimal behandling av skrøpelige eldre i slike situasjoner. 


\section{DISKUSJON}

Det er mange rapporter i litteraturen som bekrefter at eldre personer er sårbare for sykdom, skade og død i ekstreme værsituasjoner. De mest overbevisende data kommer fra de mange rapportene som omtaler hetebølger, men også kulderelaterte problemer er mer vanlig hos eldre enn andre. Andre viktige risikofaktorer er fysisk funksjonshemming, kognitiv svikt, kronisk sykdom, bruk av spesielle medisiner og sosial isolasjon. Risikofaktorene er i stor grad overlappende når det gjelder hete- og kulderelaterte problemer og det synes som dette gjelder også $i$ andre situasjoner som etter orkan, store snøfall eller jordskjelv, selv om datagrunnlaget her er svakere (tabell 1). Det er altså de skrøpelige eldre som er mest sårbare og som har den høyeste dødeligheten i ekstreme værsituasjoner. Et viktig spørsmål er om dette skyldes en såkalt "harvest"effekt, nemlig at de som er så skrøpelige at de snart skal dø får sin død fremskyndet. Litteraturen gir intet klart svar på dette.

Den mest effektive måte å forebygge heterelaterte problemer er trolig luftkondisjonering, men utbredelsen av luftkondisjonering er knyttet til sosioøkonomiske forhold slik at de fattigste vil ha minst tilgang. Luftkondisjonering i bygg som er allment tilgjengelige er derfor viktig, men vil ikke hjelpe eldre som er isolert i sine boliger. Et alarmsystem som utløses ved bestemte temperaturer og varighet kan være nyttig. Det er imidlertid kritisk å innstille alarmen riktig. Heteeller kuldealarm når det ikke er nødvendig, eller, nesten verre, å ikke alarmere når det skulle vært gjort, vil gi falsk trygghet for befolkningen. Det er derfor viktig at man i hvert land og hver region kjenner til ved hvilken temperatur (høy og/eller lav) dødeligheten vil begynne å stige raskt $(43,46,47)$. Når et slikt system aktiveres er det kritisk at riktig informasjon gis og at denne når dem som er i risiko eller deres hjelpere. Aktiveringen av et slikt system bør derfor også være knyttet til omsorgstjenester for eldre.

Under ekstreme værforhold har kommunehelsetjenesten et spesielt ansvar for eldre med funksjonssvikt og kroniske sykdommer som bor alene. Effekten av hjemmebesøk i en krisesituasjon er ikke studert, men det er indikasjoner for at slike besøk er nyttige. Oppsøkende virksomhet overfor eldre på Nordmøre etter orkanen i 1992 avdekket behov for diverse tiltak hos 150 av 2000 eldre og muligens forhindret dette noen uheldige hendelser (10). Når en slik aksjon settes i verk er det viktig at de med høyest risiko prioriteres høyest og at det er tilgang på hjelpetiltak som hjemmebasert omsorg og institusjonsopphold. Ansvaret for å organisere helse- og sosialtjenester til eldre under ekstreme værforhold må ligge både hos lokale og sentrale myndigheter, avhengig av hvor geografisk utbredt og alvorlig situasjonen er.

\section{REFERANSER}

1. Crabbe C. France caught cold by heatwave. Bull World Health Organ 2003; 81: 1169-70.

2. Belmin J. The consequences of the heat wave in August 2003 on the mortality of the elderly. Presse Med 2003; 32: 1591-4.

3. Vanhems P, Gambotti L, Fabry J. Excess rate of in-hospital deaths in Lyons, France, during the August 2003 heat wave. N Engl J Med 2003; 349: 2077-8.

4. McGeehin MA, Mirabelli M. The potential impacts of climate variability and change on temperature-related morbidity and mortality in the United States. Environ Health Perspect 2001; 109 (suppl 2): 185-9.

5. Donoghue ER, Graham MA, Jentzen JM, Lifschultz BD, Luke JL, Mirchandani HG. Criteria for diagnosis of heat-related deaths: National Association of Medical Examiners. Position paper. National Association of Medical Examiners Ad Hoc Committee on the Definition of Heat-Related Fatalities. Am J Forensic Med Pathol 1997; 18: 11-4.

6. MMWR. Hypothermia-related deaths - Philadelphia, 2001, and United States 1999. CDC 2003; 52: 86-7.

7. MMWR. Hypothermia-related deaths - Suffolk County, New York, January-March 2000, and United States 1979-1998. CDC 2001; 50: 53-7.

8. MMWR. Hypothermia-related deaths - Georgia, January 1996-December 1997, and United States, 19791995. JAMA 1999; 281: 124-5.

9. Woodhouse P, Keatinge WR, Coleshaw SR. Factors associated with hypothermia in patients admitted to a group of inner city hospitals. Lancet 1989; 2: 1201-5.

10. Ranhoff AH, Naustdal H, Skomsvoll JF. Morbidity of a hurricane disaster in Nordmoere, Norway. Tidsskr Nor Lageforen 1992; 112: 3777-80.

11. Carter AO, Millson ME, Allen DE. Epidemiologic study of death and injuries due to tornadoes. $A m J$ Epidemiol 1989; 130: 1209-18.

12. Gorjanc ML, Flanders WD, VanDerslice J, Hersh J, Malilay J. Effects of temperature and snowfall on mortality in Pennsylvania. Am J Epidemiol 1999; 149: 1152-60.

13. BBC news. Italy heat killed "4,000”. BBC News 2003: http://www.nems.bbc.co.uk/1/hi/world/europe/ 3099878.stm. 
14. Martinez Navarro F, Simon-Soria F, Lopez-Abente G. Evaluation of the impact of the heat wave in the summer of 2003 on mortality. Gac Sanit 2004; 18 (Suppl 1): 250-8.

15. Dorozynski A. Chirac announces investigation into heat wave's death toll. Br Med J 2003; $327: 465$.

16. Semenza JC, Rubin CH, Falter KH, Selanikio JD, Flanders D, Howe HL, et al. Heat-related deaths during the July 1995 heat wave in Chicago. N Engl J Med 1996; 335: 84-90.

17. Dematte JE, O'Mara K, Buescher J, Whitney CG, Forsythe S, McNamee T, et al. Near-fatal heat stroke during the 1995 heat wave in Chicago. Ann Intern Med 1998; 129: 173-81.

18. Whitman S, Good G, Donoghue ER, Bembow N, Shou W, Mou S. Mortality in Chicago attributed to the July 1995 heat wave. Am J Public Health 1997; 87: 1515-8.

19. Dixit SN, Bushara KO, Brooks BR. Epidemic heat stroke in a Midwest community: risk factors, neurological complications and sequelae. Wis Med J 1997; 96: 39-41.

20. Mirchandani HG, McDonald G, Hood IC, Fonseca C. Heat-related deaths in Philadelphia-1993. Am J Forensic Med Pathol 1996; 17: 106-8.

21. Jones TS, Liang AP, Kilbourne EM, Griffin MR, Patriarca PA, Wassilek SG, et al. Morbidity and mortality associated with the July 1980 heat wave in St Louis and Kansas City, Mo. JAMA 1982; 247: 3327-31.

22. Naughton MP, Henderson A, Mirabelli MC, Kaiser R, Wilhelm JL, Kieszak SM, et al. Heat-related mortality during a 1999 heat wave in Chicago. Am J Prev Med 2002; 22: 221-7.

23. Rajpal RC, Weisskopf MG, Rumm PD, Peterson PL, Jentzen JM, Blair K, et al. Wisconsin, July 1999 heat wave: an epidemiologic assessment. $W M J$ 2000; 99: 41-4.

24. Applegate WB, Runyan JW Jr, Brasfield L, Williams ML, Koningsberg C, Fouche C. Analysis of the 1980 heat wave in Memphis. J Am Geriatr Soc 1981; 29: 337-42.

25. Nakai S, Itoh T, Morimoto T. Deaths from heat-stroke in Japan: 1968-1994. Int J Biometeorol 1999; 43: 124-7.

26. Qiu D, Tanihata T, Aoyama H, Fujita T, Inaba Y, Minowa M. Relationship between a high mortality rate and extreme heat during the summer of 1999 in Hokkaido Perfecture, Japan. J Epidemiol 2002; 12: 254-7.

27. How CK, Chern CH, Wang LM, Lee CH. Heat stroke in a subtropical country. Am J Emerg Med 2000; 18: 474-7.

28. Faunt JD, Wilkinson TJ, Aplin P, Henschke P, Webb M, Penhall RK. The effete in the heat wave: heat-related hospital presentations during a ten day heat wave. Aust N Z J Med 1995; 25: 117-21.

29. Sartor F, Snacken R, Demuth C, Walckiers D. Temperature, ambient ozone levels, and mortality during summer 1994, in Belgium. Environ Res 1995; 70: 105-13.

30. Diaz J, Jordan A, Garcia R, Lopez C, Alberdi JC, Hernandez E, et al. Heat waves in Madrid 1986-1997: effects on the health of the elderly. Int Arch Occup Environ Health 2002; 75: 163-70.

31. Lye M, Kamal A. Effects of heatwave on mortality-rates in elderly in-patients. Lancet 1977; 1: 529-31.

32. Bucchley RW, Van Bruggen J, Truppi LE. Heat island equales death island? Environ Res 1972; 5: 85-92.

33. Clarke JF. Some effects of the urban structure on heat mortality. Environ Res 1972; 5: 93-104.

34. Marmor M. Heat wave mortality in nursing homes. Environ Res 1978; 17: 102-15.

35. Rozzini R, Zanetti E, Trabucchi M. Elevated temperature and nursing home mortality during 2003 European heat wave. J Am Med Dir Assoc 2004; 5: 138-9.

36. Sullivan-Bolyai JZ, Lumish RM, Smith EW, Howell JT, Bregman DJ, Lund M, et al. Hyperpyrexia due to airconditioning failure in a nursing home. Public Health Rep 1979; 94: 466-70.

37. Rydman RJ, Rumoro DP, Silva JC, Hogan TM, Kampe LM. The rate and risk of heat-related illness in hospital emergency departments during the 1995 Chicago heat disaster. J Med Syst 1999; 23: 41-56.

38. Cornali C, Franzoni S, Riello R, Ghianda D, Frisoni GB, Trabucchi M. Effect of high climate temperature on the behavioural and psychological symptoms of dementia. J Am Med Dir Assoc 2004; 5: 161-6.

39. Fish PD, Bennett GC, Millard PH. Heatwave morbidity and mortality in old age. Age Ageing 1985; 14: $243-5$.

40. Macey SM, Schneider DF. Deaths from excessive heat and excessive cold among the elderly. Gerontologist 1993; 33: 497-500.

41. Danzl DF, Pozos RS. Accidental hypothermia. N Engl J Med 1994; 331: 1756-60.

42. Ranhoff AH. Accidental hypothermia in the elderly. Int J Circumpolar Health 2000; 59: 255-9.

43. Bull GM, Morton J. Environment, temperature and death rates. Age Ageing 1978; 7: 210-24.

44. Bull GM. The weather and deaths from pneumonia. Lancet 1980; 1: 1405-8.

45. Laake K, Sverre JM. Winter excess mortality: a comparison between Norway and England pluss Wales. Age Ageing 1996; 25: 343-8.

46. Eurowinter Group. Cold exposure and winter mortality from ischaemic heart disease, cerebrovascular disease, respiratory disease, and all causes in warm and cold regions of Europe. Lancet 1997; 349: 1341-6.

47. Keatinge WR, Donaldson C, Cordioli E, Martinelli M, Kunst AE, Mackenbach JP, et al. Heat related mortality in warm and cold regions of Europe: observational study. BMJ 2000; 321: 670-3.

48. Braga AL, Zanobetti A, Schwartz J. The effect of weather on respiratory and cardiac deaths in 12 U.S. cities. Environ Health Perspect 2002; 110: 859-63. 
49. Curriero FC, Heiner KS, Samet JM, Zeger SL, Strug L, Patz JA. Temperature and mortality in 11 cities of the eastern United States. Am J Epidemiol 2002; 155: 80-7.

50. Donaldson GC, Keating WR, Nayha S. Changes in summer temperature and heat-related mortality since 1971 in North Carolina, South Finland and Southeast-England. Environ Res 2003; 91: 1-7.

51. Coris EE, Ramirez AM, Van Durme DJ. Heat illness in athletes: the dangerous combination of heat, humidity and exercise. Sports Med 2004; 34: 9-16.

52. Braga AL, Zanobetti A, Schwartz J. The time course of weather related deaths. Epidemiology 2001; 12: 662-7.

53. Keim SM, Guisto JA, Sullivan JB Jr. Environmental thermal stress. Ann Agric Environ Med 2002; 9: 1-15.

54. Simon HB. Hyperthermia. N Engl J Med 1993; 329: 483-7.

55. Stout RW, Crawford V. Seasonal variation in fibrinogen concentrations among elderly people. Lancet 1991; 338: $9-13$.

56. MMWR. Heat related illnesses and deaths - United States. CDC 1994-1995. 1995; 44: 577-9.

57. Kilbourne EM, Choi K, Jones TS, Thacker SB. Risk factors for heat stroke. A case-control study. JAMA 1982; 247: 3332-6.

58. Weisskopf MG, Anderson HA, Foldy S, Hanrahan LP, Blair K, Torok TJ, et al. Heat wave morbidity and mortality, Milwaukee, Wis, 1999 vs 1995: an improved response? Am J Public Health 2002; 92: 830-3.

59. Otty CJ, Roland MO. Hypothermia in the elderly: scope for prevention. BMJ 1987; 295: 419-20.

60. Kalkstein LS, Jamason PF, Green JS, Libby J, Robinson L. The Philadelphia hot weather-health watch/ warning system: Development and application, summer 1995. Bull Am Meteorol Soc 1996; 77: 1519-28.

61. Bosch X. France make heatwave plans to protect elderly people. Lancet 2004; 363: 1708.

62. Kalkstein LS. Saving life during extreme weather in summer. BMJ 2000; 321: 650-1. 